\title{
Estimation of Leaf Wetness Duration Requirements of Foliar Fungal Pathogens with Uncertain Data- An Application to Mycosphaerella nawae
}

\author{
D. Makowski, R. Bancal, and A. Vicent
}

First and second authors: INRA, UMR 211 INRA AgroParisTech, 78850 Thiverval-Grignon, France; and third author: Centro de Protección Vegetal y Biotecnología, Instituto Valenciano de Investigaciones Agrarias (IVIA), 46113 Moncada, Valencia, Spain. Accepted for publication 8 July 2011.

\begin{abstract}
Makowski, D., Bancal, R., and Vicent, A. 2011. Estimation of leaf wetness duration requirements of foliar fungal pathogens with uncertain data-An application to Mycosphaerella nawae. Phytopathology 101: 1346-1354.

Wetness of the host surface is a critical environmental factor for the development of foliar fungal diseases, but it is difficult to estimate the wetness durations required by pathogens for infection when only few experimental data are available. In this paper, we propose a method to estimate wetness duration requirements of foliar fungal pathogens when precise experimental data are not available. The proposed method is based on approximate Bayesian computation. It only requires lower and upper bounds of wetness duration requirements for one or fewer temperatures. We describe the method, show how to apply it to an infection model, and then present a case study on Mycosphaerella nawae, the
\end{abstract}

ABSTRACT causal agent of circular leaf spot of persimmon. In this example, the parameters of a simple infection model were estimated using experimental data found in the literature for the pathogen, and the model was applied to assess the risk in a Spanish area recently affected by the disease. The results showed that the probability of successful infection was higher than 0.5 for $32 \%$ of the on-site wetness durations recorded in the affected area. Results obtained with simulated data showed that our method was able to improve the estimation of wetness duration requirement. Given the flexibility of the proposed method, we expect it to become adopted for assessing the risk of introduction of exotic fungal plant pathogens.

Additional keywords: Bayesian statistics, biological invasion, pest risk analysis.
Due to the growth in global trade and the increasing concern about biosecurity, risk assessment for exotic diseases has become an emerging topic within the discipline of plant pathology $(5,21)$. Furthermore, the World Trade Organization and the International Plant Protection Convention stipulate that, in order to avoid unnecessary barriers to trade, regulatory measures should be justified on the basis of scientific pest risk assessment (PRA). Consequently, standardized guidelines for PRAs have been adopted internationally (1). Evaluating the epidemic potential of a target disease in the climate of the study area is a key component in PRA. Climate comparisons were used to determine potential geographical ranges for plant pathogens $(8,10,28,29,31,32,34,36)$. However, this approach has some limitations, especially when based only on distribution records that lack detailed epidemiological data. The absence of the disease in an area can be a consequence of an unsuitable climate as well as of the absence of inoculum, and predictions for areas with dissimilar climates can be highly inaccurate.

In the case of fungal pathogens of aerial plant parts, the climate comparison approach presents additional limitations. It is generally based on comparison of temperatures and rainfalls and does not take into account wetness of the host surface, which is a critical environmental factor for the development of these pathogens (30). Magarey et al. (23) proposed a different approach based on a generic infection model for foliar fungal pathogens.

Corresponding author: D. Makowski; E-mail address: makowski@grignon.inra.fr

doi:10.1094/PHYTO-01-11-0024

(c) 2011 The American Phytopathological Society
This model was developed primary to be used in exotic disease forecasting systems, like the NAPPFAST system implemented by the USDA-APHIS (22). The model includes several parameters describing temperature and wetness duration requirements for infection, and predicts the wetness duration required to achieve a given critical disease threshold (e.g., 20\% disease incidence or $5 \%$ disease severity) at a given temperature.

The model presented by Magarey et al. (23) computes the host surface wetness duration requirement $\left(W_{(T)}\right)$ at temperature $T$ using a temperature response function $W_{(T)}=f(T, \theta)$, where $\theta$ is a set of five unknown parameters. Once the parameters are estimated, the wetness duration requirements $W_{(T)}$ computed by the model can be compared with observed wetness durations, $\mathrm{W}_{\mathrm{obs}(T)}$, in order to determine whether wetness duration is a limiting factor for the infection process. As shown by Magarey et al. (23), the model parameters $\theta$ can be estimated from laboratory experiments in which plants are inoculated with the pathogen and incubated under different combinations of temperature and wetness duration (20). When infection studies are not available, as it is the case of many exotic pathogens, parameter values should be estimated from mycelial growth and spore germination experiments or from empirical observations of the disease in the field (23).

Parameter values derived from such experiments can be highly uncertain for some pathogens due to several reasons. A first reason is that effects of wetness duration on infection may have been experimentally tested for a limited number of temperatures only, e.g., three, four, or five temperatures. In such cases, few data are available and both extrapolation to other temperatures and model parameter estimation can be difficult using classical statistical techniques. Secondly, if only a few different wetness durations have been tested for a given temperature, it is impossible to 
derive a precise value of the wetness duration requirement, and it is therefore more logical to express the experimental results as intervals and not as point values. For example, if a critical disease intensity was achieved at $T=20^{\circ} \mathrm{C}$ with a wetness duration equal to $24 \mathrm{~h}$ but not with a duration equal to $12 \mathrm{~h}$, the true wetness duration requirement can be equal to any value between 12 and $24 \mathrm{~h}$.

The notion of wetness duration requirement itself is not fully clear. Magarey et al. (23) defined the wetness duration requirement as the wetness duration required to achieve $20 \%$ disease incidence or 5\% disease severity. However, it may be difficult to select an appropriate critical threshold in practice because such thresholds depend on the impact of the disease on crop yield, prices, and the objectives of the stakeholders (e.g., maximization of farmers' income, environmental protection). In addition, the relationship between disease intensity and crop damages is not always well known, especially when only spore germination rates are measured (11). In such cases, it would be more reasonable to consider a range of possible critical disease thresholds than only one value.

Bayesian estimation methods have become popular in many areas, especially in plant pathology $(24,26,27)$. In Bayesian statistics, data are usually related to model parameters using a likelihood function, and the posterior distribution is derived by combining the prior distribution and the likelihood function. In simple cases, the posterior distribution is computed analytically but, in most situations, the posterior distribution must be approximated using Monte Carlo methods (6). However, a limitation of these methods is that they require the definition of a likelihood function, i.e., a distribution defining the probability of the observations conditioned on the model parameters. Depending on the nature of the available data, different types of probability distributions can be used to define the likelihood (e.g., Gaussian, Binomial, and Poisson). In our situation, the definition of a likelihood function is difficult because the wetness duration requirement cannot be easily measured and only ranges of values can be defined for this variable. Approximate Bayesian computation (ABC) methods $(3,25)$ were developed to deal with this type of problem. Like other Bayesian methods, $\mathrm{ABC}$ aims at estimating a posterior probability distribution of the model parameters from both the prior distribution and experimental data. The posterior distribution defines the probability of the parameter values conditioned on the data. It corresponds to an update of the prior distribution. The difference between $\mathrm{ABC}$ and the other Bayesian techniques is that $\mathrm{ABC}$ is implemented without likelihood.

In this paper, we show how to estimate wetness duration requirements for infection by foliar fungal pathogens without precise experimental data. The proposed method is based on ABC methods, and it only requires lower and upper bounds of wetness duration requirements for one or few temperatures. It can be used to estimate the parameters of the simple infection model of Magarey et al. (23), to predict wetness duration requirements, and to perform uncertainty analysis. The method was applied in a case study on the fungal pathogen Mycosphaerella nawae Hiura \& Ikata, the causal agent of circular leaf spot of persimmon (Diospyros kaki Thunb.).

\section{MATERIALS AND METHODS}

ABC method. Consider a parametric model $f$ relating the wetness duration requirement for infection $(W)$ to temperature $(T)$ and including several unknown parameters $(\theta), W_{(T)}=f(T, \theta)$. An example is provided by Magarey et al. (23), who defined a nonlinear function including five parameters. The equations of this model are presented in the case study below. The proposed method is generic and can be implemented with other infection models like models presented by Duthie (9) and de VallavieillePope et al. (7).
Our objective is to estimate the parameters $\theta$ from two types of information: (i) prior information about values of $\theta$ derived from the literature, and (ii) possible ranges of values of $W_{(T)}$ for one or several temperatures $T$ derived from experiments. Prior information about $\theta$ should be expressed as a probability distribution reflecting the initial state of knowledge about parameter values. Different types of probability distributions can be used, such as uniform, Gaussian, etc., depending on the biological meaning of the model parameters and on prior knowledge about their values. Ranges of values of $W_{(T)}$ should be derived from results of a controlled experiment including one or several temperature-wetness duration combinations. For each tested temperature $T$, a range can be defined by a lower bound $W_{\mathrm{LOW}(T)}$ and a upper bound $W_{\mathrm{UP}(T)}$ such that $W_{\mathrm{LOW}(T)}<W_{(T)}<W_{\mathrm{UP}(T)}$ (or $W_{\mathrm{LOW}(T)}<W_{(T)} \leq$ $\left.W_{\mathrm{UP}(T)}\right)$. For example, if a critical disease intensity was achieved at $T=20^{\circ} \mathrm{C}$ with a wetness duration equal to $24 \mathrm{~h}$ but not with a duration equal to $12 \mathrm{~h}$, the range of values of $W_{(T)}$ at $T=20^{\circ} \mathrm{C}$ can be defined by $12 \mathrm{~h}<W_{(20)} \leq 24 \mathrm{~h}$. In some cases, only a lower or an upper bound can be defined from the available experimental results, especially when a precise critical disease intensity level can not be easily established. Possible ranges of values can then be defined by $W_{(T)}>W_{\mathrm{LOW}(T)}$ or $W_{(T)}<W_{\mathrm{UP}(T)}$.

Let $\pi(\theta), Y, \pi(Y \mid \theta)$, and $\pi(\theta \mid Y)$ denote the prior parameter distribution, the data, the likelihood, and the posterior parameter distribution, respectively. In our case, $Y$ should correspond to measured values of the wetness duration requirement $W$. As only ranges of values are available, it is difficult to define the likelihood $\pi(Y \mid \theta)$ and to compute the posterior distribution $\pi(\theta \mid Y)$. ABC aims at estimating the posterior distribution of the model parameters conditionally to the ranges of values defined from the exeriment. This posterior distribution can be expressed as

$$
\pi\left[\theta \mid W_{\mathrm{LOW}\left(T_{k}\right)}<W_{\left(T_{k}\right)}<W_{\mathrm{UP}\left(T_{k}\right)}, k=1, \ldots, Q\right]
$$

where $T_{k}$ is the $k$ th tested temperature in the laboratory experiment, $Q$ is the total number of tested temperatures, $W_{\mathrm{LOW}\left(T_{k}\right)}<$ $W_{\left(T_{k}\right)}<W_{\mathrm{UP}\left(T_{k}\right)}$ defines the range of possible wetness duration requirements at temperature $T_{k}$.

Rejection algorithm. We show below how the distribution (equation 1) can be estimated using the rejection algorithms presented by Marjoram et al. (25). This algorithm is based on the algorithm $C$ presented in Marjoram et al. (25) and proceeds in four steps: (i) randomly generate a candidate value $\theta$ from the prior distribution $\pi(\theta)$; (ii) calculate $W_{\left(T_{k}\right)}$ for all the tested temperature $T_{k}$ using the model $f, W\left(T_{k}\right)=f\left(T_{k}, \theta\right), k=1, \ldots, Q$, with parameter values $\theta$ generated at step i; (iii) check whether $W_{\mathrm{LOW}\left(T_{k}\right)}<W_{\left(T_{k}\right)}<W_{\mathrm{UP}\left(T_{k}\right)}$ for all temperatures $T_{k}$. $k=1, \ldots, Q$; and (iv) accept $\theta$ if the condition checked in step iii is valid and return to step i.

This algorithm does not require any burn-in period. The set of accepted parameter values can be used to estimate key features of the posterior parameter distribution (equation 1) such as mean, median, and quantiles. This set of parameter values can also be used to generate an ensemble of response curves $W_{(T)}=f(T, \theta)$ which can be conveniently described by computing mean, median, and quantile values for different temperatures.

This algorithm is easy to code (e.g., with the $\mathrm{R}$ software, www.cran-project.org) and does not require the evaluation of likelihoods. However, the accuracy of its results depends on several factors, especially on the number of iterations (i.e., on the number of Monte Carlo simulations performed at step i), on the distance between the prior distribution and the posterior distribution, on the number of wetness duration intervals $\left(W_{\mathrm{LOW}}, W_{\mathrm{UP}}\right)$ considered at step iii, and on the lengths of these intervals. The proportion of accepted parameter values at step iv can thus be very small if the posterior is a long way from the prior, if the number of wetness duration intervals is large or if these intervals are narrow. In such cases, the algorithm could become unstable 
and a large number of Monte Carlo simulations will be required at step i to stabilize the results. The appropriate number of Monte Carlo simulations can be determined by doing several implementations of the algorithm and by analyzing the stability of the results.

Case study: Wetness duration requirements for infection by ascospores of $M$. nawae. Leaf spot caused by $M$. nawae is a serious disease of persimmon that induces leaf necrosis, defoliation, and significant yield loss due to premature fruit drop. The disease is endemic in regions of Korea and Japan $(12,19)$, characterized by a humid-subtropical-type climate with a summer rainfall pattern and yearly precipitation of about $1,500 \mathrm{~mm}$. The disease has been recently detected in central-eastern Spain causing severe epidemics (4). In contrast to Korea and Japan, persimmon growing areas in Spain are characterized by a semi-arid Mediterranean-type climate. Annual precipitation rarely exceeds $500 \mathrm{~mm}$ and summers are particularly dry.

M. nawae overwinters on the leaf litter and reproduces primarily by ascospores formed in pseudothecia. Ascospores are disseminated relatively long distances by wind and infect leaves in the presence of wetness and adequate temperatures. The disease is characterized by a long incubation period and symptoms are not visible until a few weeks before harvest (13-16). In Korea, a secondary inoculum consisting of Ramularia-type conidia formed on leaf lesions has been described. Although these conidia are infectious, they are considered of minor epidemiological importance compared with ascospores $(18,19)$. In Spain, this secondary inoculum has not been observed and all lesions are thought to be caused by ascospore infections. Only experiments on spore germination and mycelial growth rates have been published (17). Therefore, we consider this disease to be a good example to evaluate the proposed methodology with uncertain data.

The rejection algorithm described above was implemented using the model of Magarey et al. (23). The wetness duration requirement $\left(W_{(T)}\right)$ at temperature $T$ is estimated from a temperature response function as follows:

$$
W_{(T)}=f(T, \theta)=\min \left[W_{\min } / h(T), W_{\max }\right]
$$

with

$$
h(T)=\left(\frac{T_{\max }-T}{T_{\max }-T_{\mathrm{opt}}}\right)\left(\frac{T-T_{\min }}{T_{\mathrm{opt}}-T_{\min }}\right)^{\left(T_{\mathrm{opt}}-T_{\min }\right) /\left(T_{\max }-T_{\mathrm{opt}}\right)}
$$

where $T_{\min }$ is the minimum temperature for infection, $T_{\max }$ is the maximum temperature for infection, $T_{\mathrm{opt}}$ is the optimum temperature for infection, $W_{\min }$ is the minimum value of wetness duration requirement for the critical disease threshold at any temperature, $W_{\max }$ is the upper boundary on the value of $W_{(T)}$ because wetness is not always a rate-limiting factor. $\theta=\left(T_{\min }, T_{\max }, T_{\mathrm{opt}}, W_{\min }\right.$, and $\left.W_{\max }\right)$ are the five model parameters. According to this model, an infection occurs when the wetness duration is higher than $W_{(T)}$. Prior distributions $\pi(\theta)$ of the five model parameters were assumed uniform with lower and upper bounds defined from the parameter estimates reported by Magarey et al. (23) for a series of

TABLE 1. Lower and upper bounds of the uniform prior distributions of the five model parameters ${ }^{\mathrm{a}}$

\begin{tabular}{lcc}
\hline Parameter & Lower bound & Upper bound \\
\hline$T_{\min }\left({ }^{\circ} \mathrm{C}\right)$ & 1 & 13.3 \\
$T_{\text {opt }}\left({ }^{\circ} \mathrm{C}\right)$ & 8.5 & 28 \\
$T_{\max }\left({ }^{\circ} \mathrm{C}\right)$ & 18 & 35 \\
$W_{\min }(\mathrm{h})$ & 2 & 48 \\
$W_{\max }(\mathrm{h})$ & 6 & 96 \\
\hline
\end{tabular}

a These bounds were derived from the estimated parameter values reported for a series of pathogenic fungi by Magarey et al. (23). pathogenic fungi (Table 1). Lower and upper bounds of the uniform distributions were set to the minimum and maximum reported estimated values after the exclusion of some very extreme values. Uniform distributions give equal weights to all values lying between the lower and upper bounds.

Data were obtained from two experiments reported in Kwon et al. (17) on ascospore germination. In one experiment, ascospore germination was measured at several temperatures, 5, 10, 15, 20, 25,30 , and $35^{\circ} \mathrm{C}$, but at only one wetness duration $(24 \mathrm{~h})$. The measured percentage of germination was equal to $100 \%$ at 15,20 , and $25^{\circ} \mathrm{C}$, was equal to 85.9 and $98.3 \%$ at 10 and $30^{\circ} \mathrm{C}$, respectively, and no germination was reported at 5 and $35^{\circ} \mathrm{C}$. In the second experiment, ascospore germination was measured at several wetness durations $(1,3,5,7,8,10,15,20$, and $24 \mathrm{~h})$ but at only one temperature $\left(20^{\circ} \mathrm{C}\right)$. No germination was reported for the durations 1 to $7 \mathrm{~h}$, the percentage of germination was over $20 \%$ with $8 \mathrm{~h}$, and $100 \%$ germination was obtained with $20 \mathrm{~h}$.

Because only spore germination percentages were available to fit the model, $W_{(T)}$ was defined as the wetness duration required at temperature $T$ to achieve a critical germination leading to successful infection. Lower and upper bounds were defined for $W_{(T)}$ based on the experimental results reported above. These bounds were defined without any strong assumption about critical germination threshold; we only assumed that germination percentage needed to be higher than zero and lower than $100 \%$. The lower bound $W_{\text {LOW(T) }}$ was defined as the highest wetness duration leading to $0 \%$ germination among the tested durations at temperature $T$, and the upper bound $W_{\mathrm{UP}(T)}$ was defined as the lowest duration leading to $100 \%$ germination among the tested durations at temperature $T$. One hundred percent germination was obtained at $15^{\circ} \mathrm{C} / 24 \mathrm{~h}$ and $25^{\circ} \mathrm{C} / 24 \mathrm{~h}$ (first experiment), and we set $W\left(15^{\circ} \mathrm{C}\right)$ $<24 \mathrm{~h}$ and $W\left(25^{\circ} \mathrm{C}\right)<24 \mathrm{~h}$. One hundred percent germination was reported at $20^{\circ} \mathrm{C} / 20 \mathrm{~h}$ (second experiment), and we set $W\left(20^{\circ} \mathrm{C}\right)<20 \mathrm{~h}$. Finally, 0 and $20 \%$ germination were recorded at $20^{\circ} \mathrm{C} / 7 \mathrm{~h}$ and $20^{\circ} \mathrm{C} / 8 \mathrm{~h}$, respectively, and we set $W\left(20^{\circ} \mathrm{C}\right)>7 \mathrm{~h}$.

The rejection algorithm was implemented in order to estimate the posterior distribution defined by

$$
\pi\left[\theta \mid W\left(15^{\circ} \mathrm{C}\right)<24 \mathrm{~h}, 7 \mathrm{~h}<W\left(20^{\circ} \mathrm{C}\right)<20 \mathrm{~h}, W\left(25^{\circ} \mathrm{C}\right)<24 \mathrm{~h}\right]
$$

The number of iterations was set equal to 50,000, and the computations were replicated five times in order to assess the stability of the results. Parameter values were randomly generated at step i of the algorithm from the prior distributions. Due to the overlap of the uniform prior parameter distributions, constraints on parameter values were considered at this step in order to satisfy $T_{\max }>T_{\text {opt }}>T_{\min }$ and $W_{\max }>W_{\min }$. Without these constraints, some of the values of $T_{\max }$ and $T_{\text {opt }}$ would have been lower than $T_{\min }$, and some of the values of $W_{\max }$ would have been lower than $W_{\min }$. The acceptance rate of the algorithm at step iv was equal to $9.2 \%$. The posterior distributions of the model parameters and of the resulting model outputs were described by computing mean, median, standard deviation, 5, 25, 75, and 95\% percentiles over the $0.092 * 50,000$ Monte Carlo simulations accepted by the algorithm.

The posterior distribution was used to compute the probability that wetness durations recorded in the Spanish site Alzira (located in a persimmon growing area) were higher than the predicted duration requirements. This probability was defined by

$$
\operatorname{Pr}\left[f(T, \theta)<W_{\mathrm{obs}(T)}\right.
$$

where $W_{\mathrm{obs}(T)}$ is a wetness duration recorded at temperature $T$. The probability (equation 4) was computed for 672 wetness periods recorded from September 2007 to July 2010. Hourly temperature and leaf wetness were monitored with automated weather stations (Watch Dog Data logger 450. Spectrum Technologies Inc., Plainfield, IL) equipped with a resistance-type leaf wetness sensor. 
Environmental monitors were located between two trees on the central row of each orchard at $1.5 \mathrm{~m}$ above the soil surface. The electronic wetness sensor faced north at an angle of $30^{\circ}$ to the horizontal. The wetness threshold was adjusted at the beginning of the study using a paper string wetness recorder (Bazier, Jules Richard; Argenteuil, France) and visual observations. Two series of probabilities were computed successively; one with the prior parameter distribution, one with the posterior distribution (2). All computations were done using the $\mathrm{R}$ software v.2.11.1 (www.cran-project.org). The code is available upon request.

Simulation study: Performance of the method as a function of the number of data. A simulation study was carried out in order to assess the performance of the method. An artificial fungus species was created for this purpose. It was assumed that the true parameter values of this species were equal to $T_{\min }=5^{\circ} \mathrm{C}$, $T_{\text {opt }}=25^{\circ} \mathrm{C}, T_{\max }=34^{\circ} \mathrm{C}, W_{\text {min }}=10 \mathrm{~h}$, and $W_{\text {max }}=23 \mathrm{~h}$, and the corresponding response of $W$ to $T$ (i.e., the true response of the artificial fungus species) was computed. Artificial data were simulated from the true response curve in order to evaluate the ability of the rejection algorithm to recover the true response of $W$ to $T$ in function of the number of data. Data were simulated according to five scenarios ( $\mathrm{S} 1$ to $\mathrm{S} 5$ ) corresponding to five different experimental designs:

- S1: One tested temprature, $T=25^{\circ} \mathrm{C}$, and one tested wetness duration, $W=20 \mathrm{~h}$.

- S2: One tested temperature, $T=15^{\circ} \mathrm{C}$, and five tested wetness durations, $W=8,12,16,20$, and $24 \mathrm{~h}$.

- S3: One tested temperature, $T=25^{\circ} \mathrm{C}$, and five tested wetness durations, $W=8,12,16,20$, and $24 \mathrm{~h}$.

- S4: One tested temperature, $T=35^{\circ} \mathrm{C}$, and five tested wetness durations, $W=8,12,16,20$, and $24 \mathrm{~h}$.

- S5: Three tested temperatures, $T=15,25,35^{\circ} \mathrm{C}$, and five tested wetness durations for each temperature, $W=8,12,16$, 20 , and $24 \mathrm{~h}$.

An upper bound $W_{\mathrm{UP}}(T)$ was defined from the computed response for each tested temperature $T$ and each scenario. A lower bound $W_{\text {LOW }}(T)$ was also defined for each tested temperature $T$ for the last four scenarios. These scenarios differed on the tested temperatures (equal to the true value of $T_{\text {opt }}$ in S1, S3, and S5, but different from the true value of $T_{\mathrm{opt}}$ in the other scenarios) and on the number of tested wetness durations (i.e., the number of data available to run the rejection algorithm).

The rejection algorithm was implemented for each scenario with 50,000 iterations and the posterior means of $W$ were compared with the true response both graphically and by computing mean squared errors (MSE).

\section{RESULTS}

Prior and posterior distributions for M. nawae. Prior and posterior distributions of parameter values obtained for $M$. nawae were summarized by their mean, median, standard deviation, and 5 and $95 \%$ percentiles (Table 2). Posterior means of $T_{\min }$ and $T_{\mathrm{opt}}$ were slightly decreased compared with prior means (by less than $5 \%$ ), whereas the posterior mean of $T_{\max }$ was $8 \%$ higher than its prior mean. The posterior standard deviations of the three tem- perature parameters were slightly decreased compared with their prior standard deviations. The length of the interval defined by the 5 and $95 \%$ percentiles of $T_{\text {opt }}$ was smaller in the posterior distribution than the prior. This is confirmed in Figure 1 where the posterior distribution of $T_{\mathrm{opt}}$ showed a more peaked (kurtosis = -0.81) shape than the prior (kurtosis $=-1.15$ ). The posterior distribution of $T_{\max }$ was more skewed toward high values than the prior (Fig. 1), and the $5 \%$ quantile of $T_{\max }$ was higher with the posterior distribution (Table 2).

Posterior means and medians of $W_{\min }$ and $W_{\max }$ were decreased by more than $30 \%$ compared with their prior values. The standard deviation of $W_{\min }$ was also decreased. The difference between the 5 and $95 \%$ percentiles were much smaller in the posterior distribution of $W_{\min }$ than in the prior $(11.8 \mathrm{~h}$ versus $41.4 \mathrm{~h})$. Figure 2 shows that the posterior distribution of $W_{\min }$ is much more peaked (kurtosis $=-0.47$ ) than the prior (kurtosis $=-1.19$ ). The posterior standard deviation of $W_{\max }$ was slightly higher than the prior $(26.7 \mathrm{~h}$ versus $27.8 \mathrm{~h})$. However, the 5 and $95 \%$ percentiles obtained for this parameter were smaller in the posterior distribution than in the prior distribution (Table 2), and the posterior distribution of $W_{\max }$ was skewed toward small values.

The results were consistent across the five series of computations performed to assess the stability of the algorithm. For example, the five posterior means of $W_{\min }$ ranged from 10.31 to $10.45 \mathrm{~h}$, and the five posterior standard deviations of this parameter ranged from 3.53 to $3.64 \mathrm{~h}$. The results of the rejection algorithm were thus stable with 50,000 Monte Carlo simulations.

Figure 2 shows the prior and posterior distributions of the model outputs resulting from the prior and posterior parameter distributions presented in Figure 1. The range of wetness durations covered by the prior distribution was very large; from 2 to $96 \mathrm{~h}$ (Fig. 2A). This is due to the chosen prior parameter distribution being defined from parameter values estimated for a large series of species with different characteristics. The range of wetness duration values covered by the posterior distribution is much narrower for temperatures between 10 and $30^{\circ} \mathrm{C}$. The use of the lower and upper bounds $\left(W_{\mathrm{LOW}}\right.$ and $\left.W_{\mathrm{UP}}\right)$ defined from experimental data led to a strong reduction of the uncertainty about wetness duration requirement of $M$. nawae for these temperatures. Compared with the prior distributions, the quantiles obtained with the posterior distribution of the model outputs were systematically lower, and the predicted wetness duration requirements were lower with the posterior distribution. The shape of the posterior distribution was different from the shape of the prior distribution. The prior distribution of the model output was nearly symmetrical for all temperatures, whereas the posterior distribution was skewed toward low wetness durations for the high and low temperatures $\left(T>30^{\circ} \mathrm{C}\right.$ and $\left.T<10^{\circ} \mathrm{C}\right)$.

Figure 3 shows the probabilities for the 672 wetness durations recorded in Alzira (Spain) to be higher than the estimated duration requirements (equation 4). Probabilities were computed using either the prior distribution (Fig. 3B) or the posterior distribution (Fig. 3C). A probability close to 1 indicates a high chance for the recorded wetness duration to be higher than the wetness duration required by $M$. nawae. On the other hand, a probability close to zero indicates a low chance for the recorded wetness duration to be sufficiently high to meet the estimated fungus requirement.

TABLE 2. Main characteristics of the prior and posterior distributions of the five model parameters for Mycosphaerella nawae ${ }^{\mathrm{a}}$

\begin{tabular}{|c|c|c|c|c|c|c|c|c|c|c|}
\hline \multirow[b]{2}{*}{ Parameter } & \multicolumn{5}{|c|}{ Prior distribution } & \multicolumn{5}{|c|}{ Posterior distribution } \\
\hline & Mean & Median & $5 \%$ & $95 \%$ & SD & Mean & Median & $5 \%$ & $95 \%$ & $\mathrm{SD}$ \\
\hline$T_{\min }\left({ }^{\circ} \mathrm{C}\right)$ & 7.13 & 7.09 & 1.61 & 12.70 & 3.56 & 6.81 & 6.61 & 1.58 & 12.56 & 3.49 \\
\hline$T_{\text {opt }}\left({ }^{\circ} \mathrm{C}\right)$ & 18.67 & 18.70 & 9.91 & 27.10 & 5.45 & 18.20 & 18.51 & 10.00 & 25.83 & 4.73 \\
\hline$T_{\max }\left({ }^{\circ} \mathrm{C}\right)$ & 27.80 & 28.26 & 19.65 & 34.32 & 4.56 & 30.08 & 31.03 & 21.26 & 34.65 & 4.01 \\
\hline$W_{\min }(\mathrm{h})$ & 24.98 & 24.91 & 4.32 & 45.74 & 13.26 & 10.31 & 9.78 & 5.08 & 16.89 & 3.59 \\
\hline$W_{\max }(\mathrm{h})$ & 60.64 & 61.86 & 22.27 & 92.63 & 21.79 & 42.38 & 35.69 & 11.48 & 89.76 & 26.68 \\
\hline
\end{tabular}

a Mean, median, $5 \%$ percentile, $95 \%$ percentiles, and standard deviation (SD) estimated from 50,000 Monte Carlo simulations. 
Results showed that, when computed from the prior, most of the calculated probabilities were close to zero. Only 3\% of the 672 probabilities were higher than 0.5 and only $1 \%$ of these probabilities were higher than 0.8 (Fig. 3B). The probabilities computed from the posterior (Fig. 3C) were much higher: $32 \%$ of the 672 probabilities were higher than 0.5 and $8 \%$ of these probabilities were higher than 0.8 (Fig. 3B). According to the posterior distribution, almost one third of the wetness periods recorded in Alzira are thus likely to meet the fungus requirement.

Simulation study: Assessment of the estimated responses. In the simulation study, the experimental design of the scenario S1 only includes one temperature $\left(25^{\circ} \mathrm{C}\right)$ and one wetness duration $(20 \mathrm{~h})$. According to the response curve obtained with the true parameter values, the wetness duration requirement for $T=25^{\circ} \mathrm{C}$ is lower than $20 \mathrm{~h}$. For scenario $\mathrm{S} 1$, the posterior distribution was thus computed using the rejection algorithm $(50,000$ iterations) with an upper bound set to $20 \mathrm{~h}\left(W\left(20^{\circ} \mathrm{C}\right)<20 \mathrm{~h}\right)$. The prior means of the model outputs and posterior means are both presented as a function of the temperature in Figure 4. The posterior means were closer to the true wetness duration requirements than the prior means; the MSE was equal to 1,015.6 and 256.6 with the prior and posterior means, respectively. Wetness duration requirements were overestimated by both prior and posterior means. However, for temperatures between 15 and $25^{\circ} \mathrm{C}$, the estimated wetness duration requirements provided by the posterior means were closer to the true values and wetness duration requirements were overestimated by less than $4 \mathrm{~h}$. For temperatures lower than $15^{\circ} \mathrm{C}$ and higher than $25^{\circ} \mathrm{C}$, differences between posterior means and true values were larger, but were still smaller than differences between prior means and true values (Fig. 4). The use of a single upper bound of wetness duration defined for a single temperature thus considerably improved the estimation of the wetness duration requirements.

Figure 5 shows the results obtained for scenarios S2 to S5. Wetness duration lower and upper bounds were defined from the true response at 15,25 , and $35^{\circ} \mathrm{C}$, assuming that wetness durations $8,12,16,20$, and $24 \mathrm{~h}$ were tested at each temperature. In scenario S2, a single temperature $T=15^{\circ} \mathrm{C}$ was considered, and wetness duration lower and upper bounds were set equal to 20 and $24 \mathrm{~h}$, respectively $(20<W(15)<24 \mathrm{~h})$, based on the true response. The posterior means obtained in this scenario were close to the true wetness duration requirement at $T=15^{\circ} \mathrm{C}$ (difference between the true value and the posterior mean equal to $0.3 \mathrm{~h}$ at this temperature), but the estimations were less accurate for other temperatures. The MSE was equal to 596.9 and was thus higher than the MSE obtained with S1 (256.6), but this value was lower than the MSE obtained with the prior means $(1,015.6)$.

In scenario $\mathrm{S} 3$, a single temperature equal to $25^{\circ} \mathrm{C}$ was considered, and wetness duration lower and upper bounds were set equal to 8 and $12 \mathrm{~h}$, respectively, for this temperature $(8<W(25)<$ 12). The results obtained in this scenario were similar to the results obtained with scenario S1: the MSE was equal to 252.4 and was close from the MSE obtained with S1 (256.6). Estimations provided by the posterior means overestimated duration requirements, but differences with true values were lower than $3 \mathrm{~h}$ for temperatures in the range 15 to $25^{\circ} \mathrm{C}$.
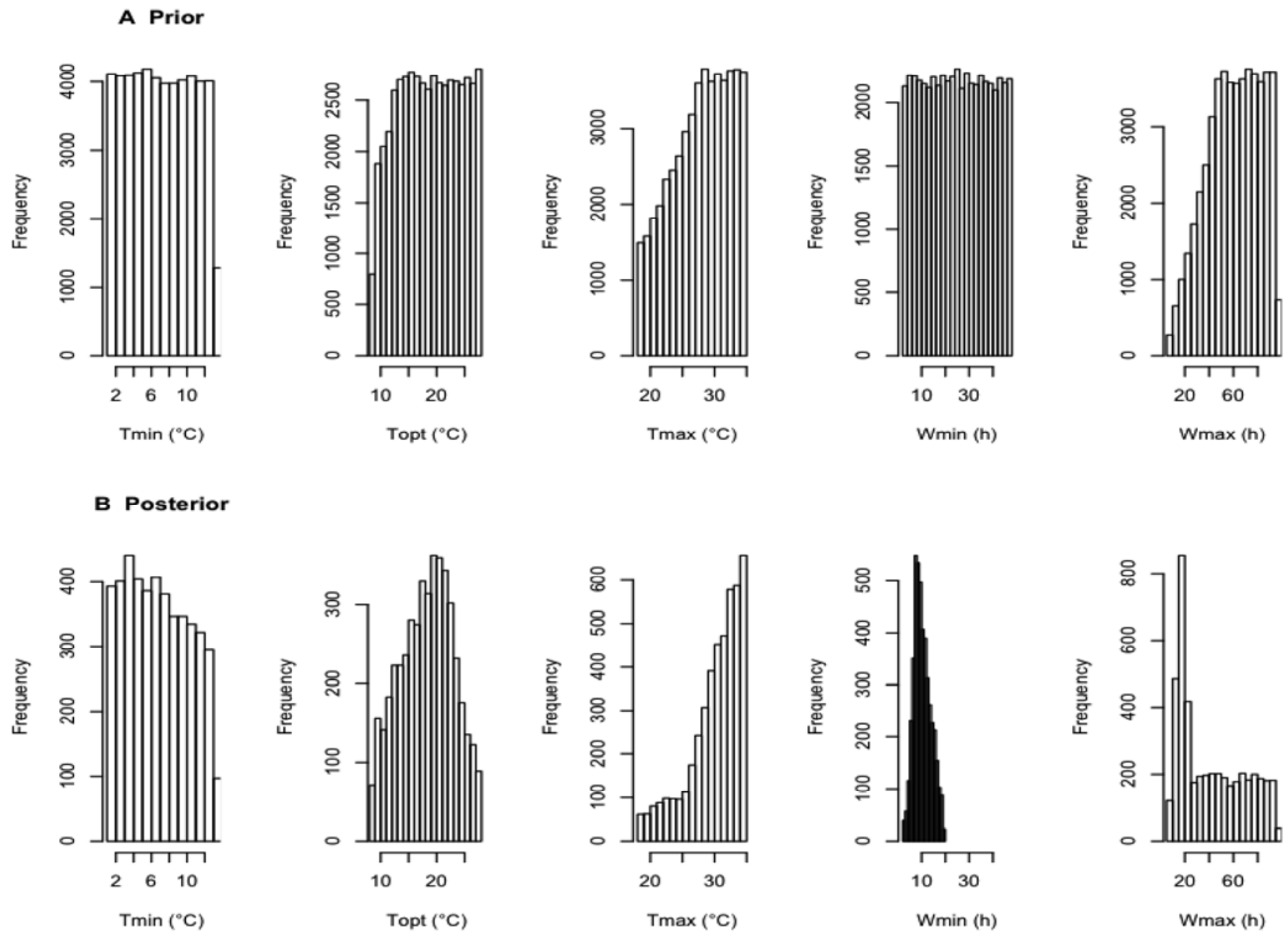

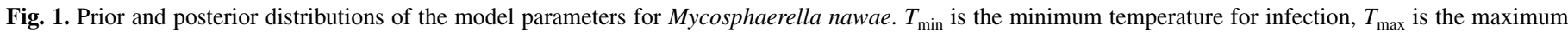

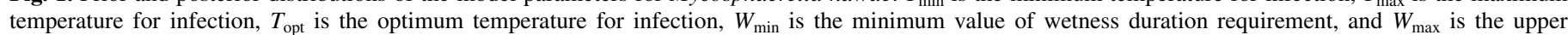
boundary on the wetness duration requirement. 
In scenario $\mathrm{S} 4$, a single temperature equal to $35^{\circ} \mathrm{C}$ was considered, and wetness duration lower and upper bounds were set equal to 20 and $24 \mathrm{~h}$, respectively, for this temperature $(20<$ $W(35)<24)$. The MSE was equal to 23.98 in this scenario. The estimations provided by the posterior means were close to the true values for all temperatures, but the optimal temperature (i.e., the temperature minimizing the wetness duration requirement) was underestimated (Fig. 5).
A Prior

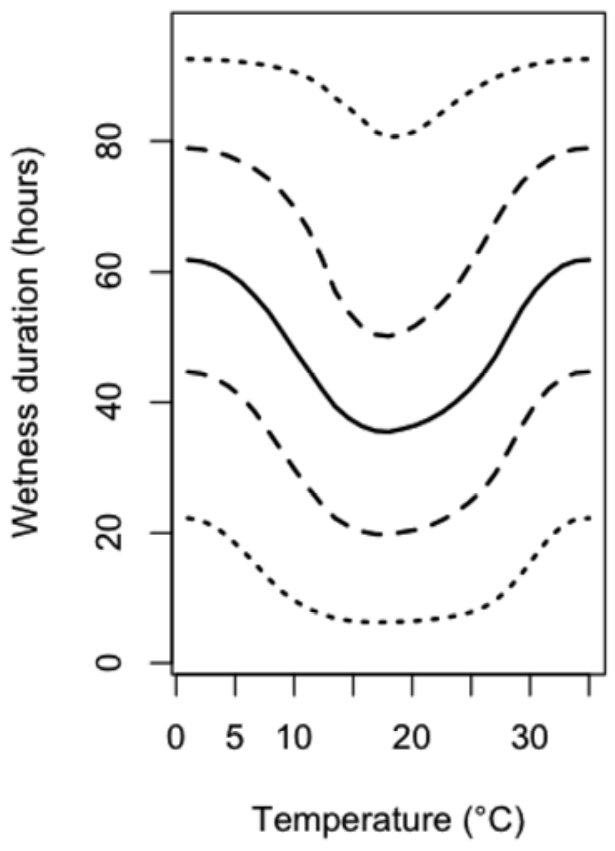

B Posterior

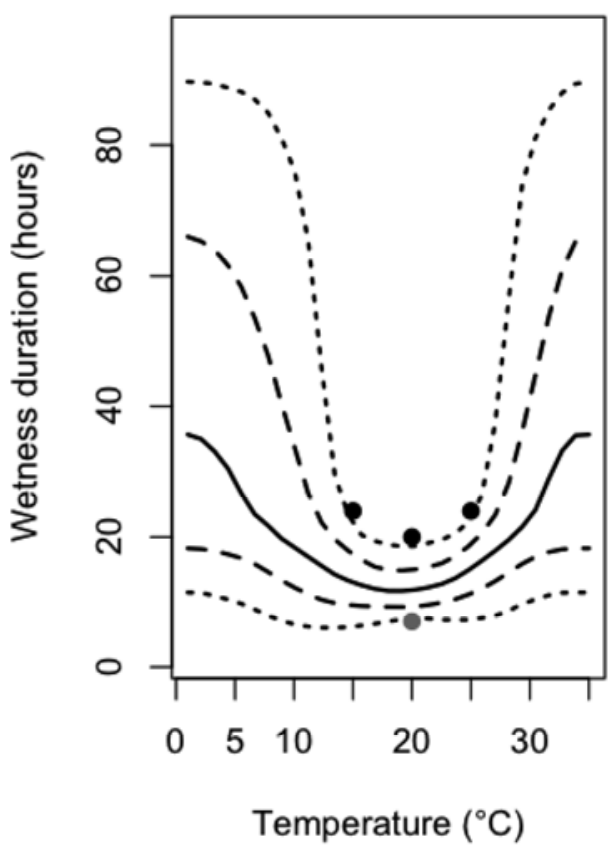

Fig. 2. Prior and posterior distributions of the model outputs for Mycosphaerella nawae; 5 and $95 \%$ percentiles (dotted lines), first and third quartiles (dashed lines), and median (continuous line). Black points indicate the upper bounds of wetness durations used for parameter estimation at $T=15,20$, and $25^{\circ} \mathrm{C}$. The gray point indicates the lower bound considered at $T=20^{\circ} \mathrm{C}$.

A

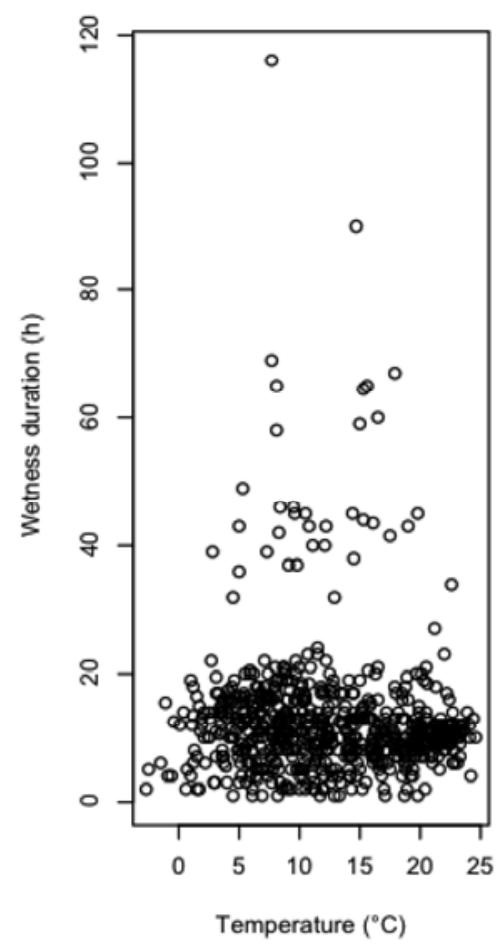

B Prior

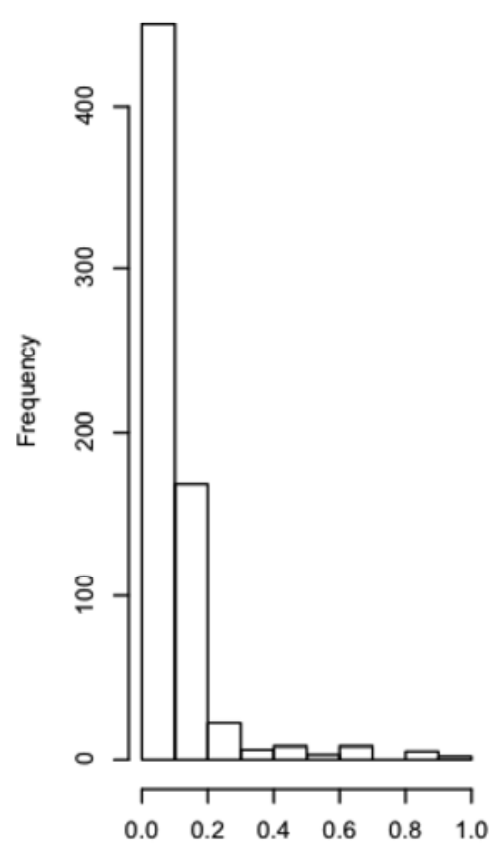

Probability to reach required wetness
C Posterior

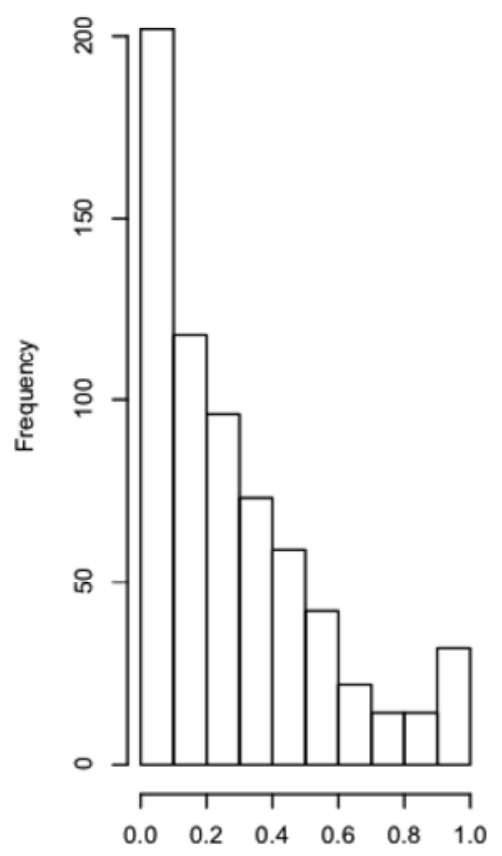

Probability to reach required wetness

Fig. 3. A, Recorded wetness durations and temperatures during 672 wetness periods in Alzira (Spain), and histograms of the corresponding 672 probabilities that the recorded wetness durations are higher than the required wetness durations. These probabilities were computed from the $\mathbf{B}$, prior distribution and $\mathbf{C}$, posterior distribution for Mycosphaerella nawae. 


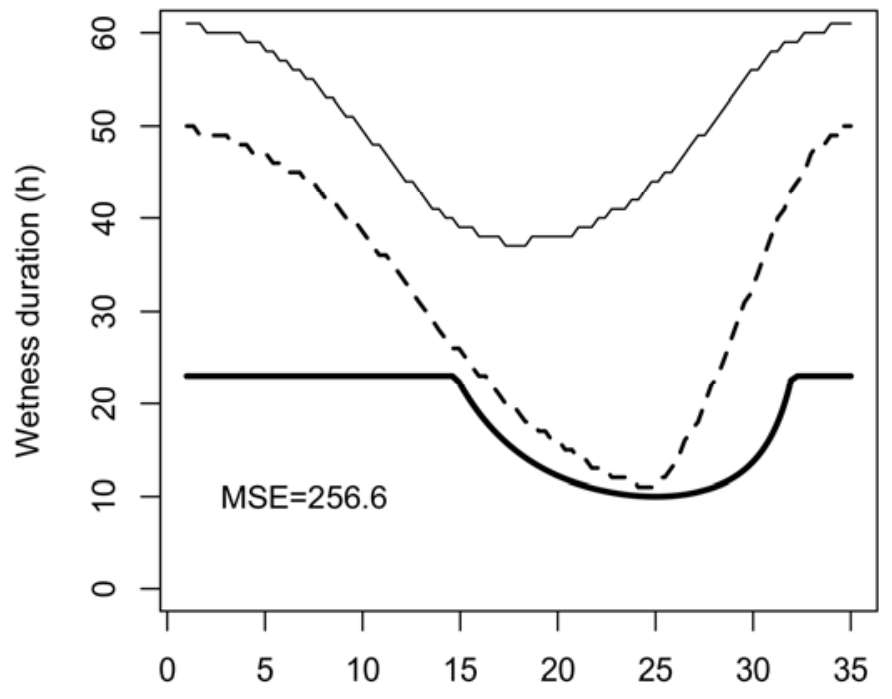

Temperature $\left({ }^{\circ} \mathrm{C}\right)$

Fig. 4. Simulation study: Comparison of the true response curve (thick continuous line) with the response curves estimated by the prior mean (thin continuous line) and by the posterior mean (dashed line). Scenario S1. MSE corresponds to the mean square error computed from the true response curve and the posterior mean.

The best wetness duration requirement estimations were obtained in scenario S5 where three temperatures and their corresponding wetness duration lower and upper bounds were all used together to compute the posterior means $(\mathrm{MSE}=9.45)$. In this scenario, the estimated response provided by the posterior means were close to the true values for all temperatures and the optimal temperature was correctly estimated (Fig. 5).

\section{DISCUSSION}

In this paper, we presented a Bayesian method based on Monte Carlo simulations to estimate wetness duration requirements for infection without precise experimental data. The main idea is to estimate the parameters of a simple infection model (23) from wetness duration intervals derived from experiments. The proposed method has several advantages. It only requires lower and upper bounds of wetness duration requirements for one or several temperatures and can thus be implemented when only few experimental data from the target species are available in the literature. This method does not require the specification of a precise critical disease intensity threshold such as $20 \%$ disease incidence or $5 \%$ severity (23). This is an important advantage because the choice of such thresholds is often difficult, especially when the impacts of the disease on plant growth or crop yield are not well known or are highly variable.

The method can take into account expert knowledge about parameter values. Candidate parameter values are randomly generated from a prior parameter probability distribution. This prior distribution describes the initial stage of knowledge about model parameter values, before using experimental data. It should be defined from plausible values found in the scientific literature or in technical reports. When no information about parameter values is available, it is possible to define a prior probability distribution covering large ranges of possible parameters values.

Another interest of the proposed method is that it provides information on the uncertainty, which is an inherent part of PRAs (1). This method computes posterior probability distributions for model parameters and estimated wetness duration requirements. These distributions can be used to compute extreme quantiles (e.g., 5 and $95 \%$ percentile) for parameter values and wetness duration requirements, and to compute the probability that some recorded wetness durations would exceed the estimated duration requirements. Another advantage is that the method is based on a simple algorithm that is easy to code with any programming language and could be included in decision support tools developed for risk analysis like NAPPFAST (22).

In addition to infection, disease development depends on other components of the pathogen life cycle; incubation, sporulation, dissemination, and survival. However, these components will be unable to occur without successful infection and, for exotic pathogens, data on other elements of the life cycle are rarely available. The proposed method could be useful for risk assessors who need to estimate wetness duration requirements for infection of invasive pathogens. Epidemiological knowledge of invasive fungi is often limited and their impact on plants is not always well known (35). It is thus often difficult to derive precise values of wetness duration from published experimental data for these species. Our approach could help risk assessors to estimate the response of wetness duration requirements for infection to temperature, and to analyze the uncertainty of the estimated values. Model outputs should be interpreted considering the interactions of other factors such as availability and connectivity of susceptible hosts, potential inoculum dynamics, and reproductive traits of the pathogen.

The utility of the method was illustrated in a case study on $M$. nawae, a fungal pathogen of persimmon. We used data on spore germination published in Korea to define lower and upper bounds of wetness duration requirements for infection. The relationships between germination, disease incidence, and persimmon production were not established for this pathogen, and the number of tested temperature-wetness combinations was quite limited. It was not possible to deduce precise wetness duration requirements from the available data, but we were able to define lower and upper bounds without any arbitrary assumption about the critical germination threshold. Although only very few data were published for this pathogen, results obtained with our method showed that the climatic conditions recorded in one location in Spain were compatible with the estimated wetness duration requirements. Before its detection in Spain, circular leaf spot of persimmon was restricted to the agroclimatic region of Korea and Japan. Based on classic climatic comparisons, the emergence of the disease in a semi-arid area was completely unexpected (33). This case study showed that our method can provide risk assessors with useful results, even when the number of published data is limited.

The performance of the proposed method depends on several factors. In our applications, we used the model presented by Magarey et al. (23). This model has several advantages: its parameters have biological interpretations and the model is simple and generic. However, our method could be implemented with other models such as those proposed by Duthie (9), and it will be interesting to compare results obtained with different models. Models may differ in how well the ABC approach works.

The method performance may also be influenced by the prior probability used to generate the candidate parameter values at step $i$ of the algorithm. In this study, we used uniform distributions with lower and upper bounds defined to cover the wide ranges of parameter values reported by Magarey et al. (23) for many fungal pathogens. Other prior distributions could be defined when specific information about parameter values is available. The choice of the prior distribution may have an effect on the required number of iterations needed to reach stable results with the rejection algorithm. A high number of iterations is needed when the prior is a long way from the posterior distribution (25).

The type of experimental data used to define wetness duration intervals also influences the performance of the method. Our simulation study showed that the accuracy of the estimated wetness duration requirements depends on the experimental design, especially on the number and values of the tested temperatures. In 
$\mathbf{T}=15$

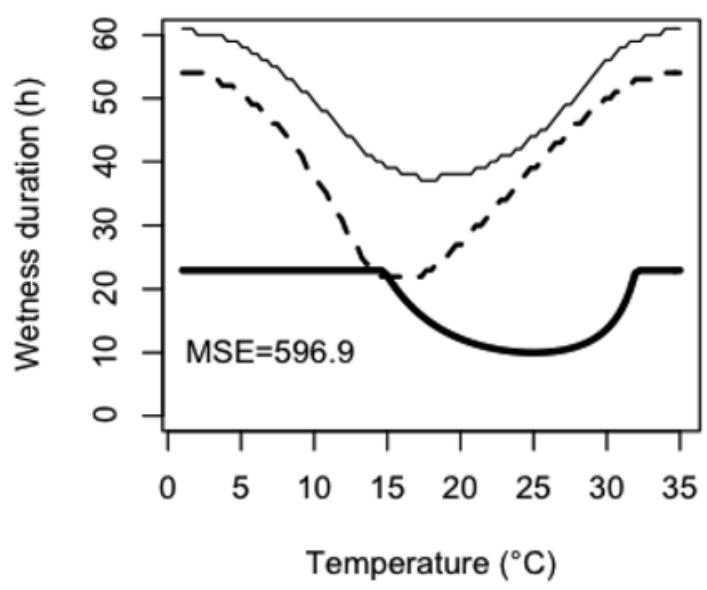

$\mathbf{T}=\mathbf{3 5}$

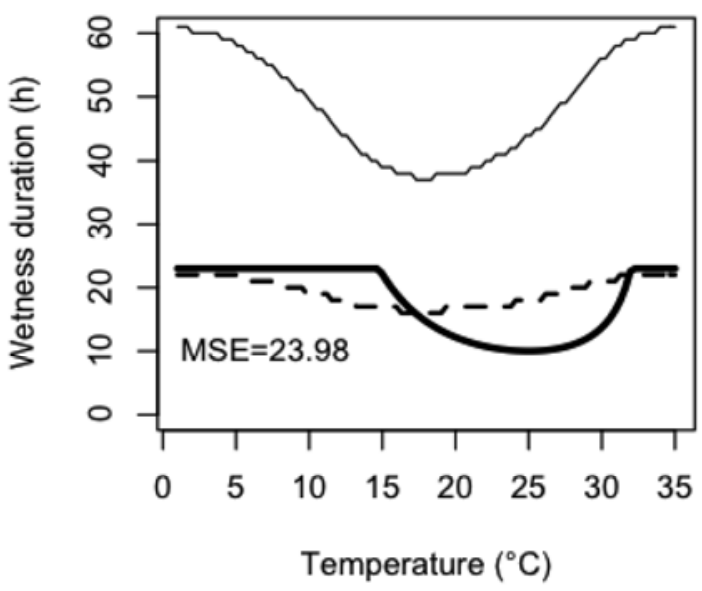

$\mathbf{T}=\mathbf{2 5}$

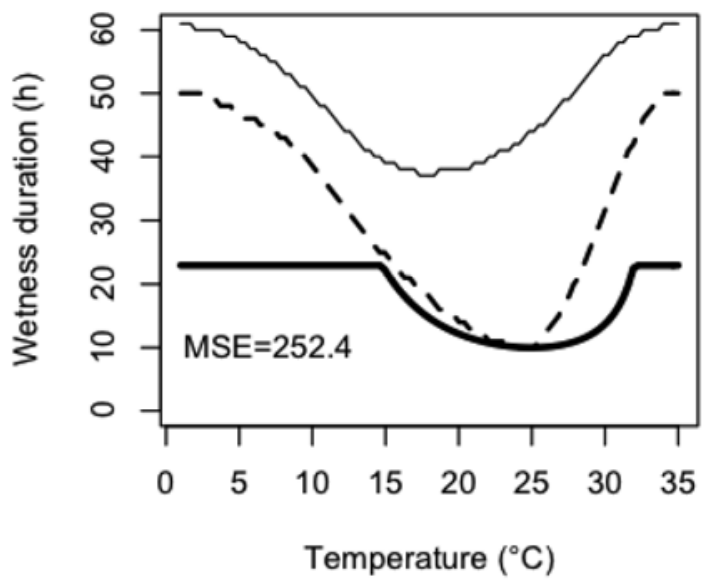

$T=15,25,35$

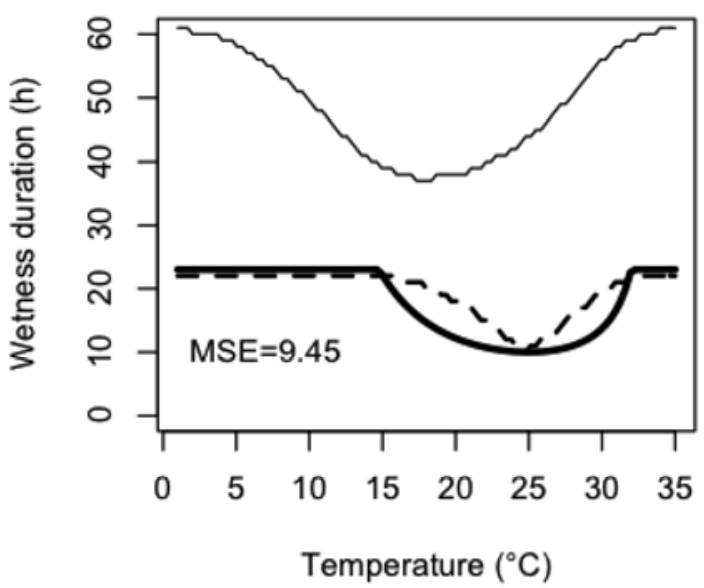

Fig. 5. Simulation study: Comparison of the true response curve (thick continuous line) with the response curves estimated by the prior mean (thin continuous line) and by the posterior mean (dashed line). Scenarios $\mathrm{S} 2\left(T=15^{\circ} \mathrm{C}\right)$, scenario $\mathrm{S} 3\left(T=25^{\circ} \mathrm{C}\right)$, scenario $\mathrm{S} 4\left(T=35^{\circ} \mathrm{C}\right)$, and scenario $\mathrm{S} 5\left(T=15,25\right.$, and $\left.35^{\circ} \mathrm{C}\right)$. MSE corresponds to the mean square errors (MSE) computed from the true response curve and the posterior mean.

our simulation study, estimated values were more accurate with experiments including three temperatures than with experiments including only one temperature. However, in all the considered scenarios, the posterior means of the model outputs were always closer to the true values than the prior means.

Bayesian inference techniques like MCMC have attracted a lot of interest since the last two decades in many different areas, especially in plant pathology $(24,26,27)$. These approaches are powerful but require that we can compute the likelihood function, i.e., the probability of obtaining the observations given some parameter values. Since the likelihood can be difficult to compute, ABC method (also named likelihood-free inference) has been developed to avoid the need for a likelihood function. This approach was first applied in population genetics (3) and is increasingly used in other fields (2), but has not been applied in plant pathology so far. The rejection algorithm used in this study is one of the simplest algorithms developed for ABC method. It has several advantages; it is easy to code, does not require a burnin period, and can use parallel computations (25). This algorithm performed well in our application and led to stable results with a reasonable number of Monte Carlo simulations $(50,000)$. However, this algorithm may require a very high number of simulations to solve more complex problems and, in such cases, the use of more sophisticated ABC algorithms could be useful $(2,3,25)$.

\section{ACKNOWLEDGMENTS}

The work of the first two authors was partly funded by the European project PRATIQUE (7th Framework Programme for Research and Technological Development). We thank G. Stancanelli and O. MosbachSchulz from the European Food Safety Authority for useful discussion and J. Wilcox for correcting the English language.

\section{LITERATURE CITED}

1. Anonymous. 1995. International Standards for Phytosanitary Measures. Guidelines for Pest Risk Analysis. International Plant Protection Convention, Food, and Agriculture Organization of the United Nations.

2. Beaumont, M. A. 2010. Approximate Bayesian Computation in evolution and ecology. Annu. Rev. Ecol. Evol. S. 41:379-406.

3. Beaumont, M. A., Zhang, W. Y., and Balding, D. J. 2002. Approximate Bayesian computation in population genetics. Genetics 162:2025-2035.

4. Berbegal, M., Pérez-Sierra, A., Armengol, J., Park, C. S., and GarcíaJiménez, J. 2010. First report of circular leaf spot of persimmon caused by Mycosphaerella nawae in Spain. Plant Dis. 94:374.

5. Campbell, F. T. 2001. The science of risk assessment for phytosanitary regulation and the impact of changing trade regulations. Bioscience 51:148-153.

6. Carlin, B. P., and Louis, T. A. 2008. Bayesian Methods for Data Analysis. Chapman \& Hall/CRC Press, Boca Raton, FL.

7. de Vallavieille-Pope, C., Huber, L., Leconte, M., and Goyeau, H. 1995. Comparative effects of temperature and interrupted wet periods on 
germination, penetration, and infection of Puccinia recondita $\mathrm{f}$. $\mathrm{sp}$. tritici and $P$. striiformis on wheat seedlings. Phytopathology 85:409-415.

8. Desprez-Loustau, M. L., Robin, C., Reynaud, G., Deque, M., Badeau, V., Piou, D., Husson, C., and Marcais, B. 2007. Simulating the effects of a climate change scenario on the geographical range and activity of forest pathogenic fungi. Can. J. Plant Pathol. 29:101-120.

9. Duthie, J. A. 1997. Models of the response of foliar parasites to the combined effects of temperature and duration of wetness. Phytopathology 87:1088-1095.

10. Ganley, R. J., Watt, M. S., Manning, L., and Iturritxa, E. 2009. A global climatic risk assessment of pitch canker disease. Can. J. For. Res. 39:2246-2256.

11. Gäumann, E. 1950. Principles of Plant Infection. Hafner Publishing Company, New York.

12. Ikata, S., and Hitomi, T. 1929. Studies on circular leaf spot of persimmon caused by Mycosphaerella nawae. Spec. Bull. Okayama Pref. Agric. Exp. Stn. 33:1-36. (In Japanese).

13. Kang, S. W., Kwon, J. H., Lee, Y. S., and Park, C. S. 1993. Effects of meteorological factors on perithecial formation and release of ascospores of Mycosphaerella nawae from the overwintered persimmon. RDA J. Agric. Sci. 35:337-343. (In Korean, abstract in English).

14. Kwon, J., Kang, S., Cho, D., Shin, W., Park, C., and Kim, H. 1997. Factor of affecting ascospore release of Mycosphaerella nawae causing spotted leaf casting of persimmon. RDA J. Crop Prot. 39:10-14. (In Korean, abstract in English).

15. Kwon, J., Kang, S., Chung, B., and Park, C. 1995. Environmental factors affecting ascospore release of Mycosphaerella nawae, the causal organism of the spotted leaf casting of persimmon. Korean J. Plant Pathol. 11:344-347. (In Korean, abstract in English).

16. Kwon, J., Kang, S., Park, C., and Kim, H. 1997. Environmental factors affecting maturation rate of pseudothecia of Mycosphaerella nawae, the causal organism of the spotted leaf casting of persimmon. Korean J. Plant Pathol. 13:215-218. (In Korean, abstract in English).

17. Kwon, J., Kang, S., Park, C., and Kim, H. 1998. Difference in temperature profiles optimum for germination of either ascospore and/or conidia, signifies the release as primary inoculum or secondary inoculum, respectively. RDA J. Crop Prot. 40:80-82. (In Korean, abstract in English).

18. Kwon, J., Kang, S., Park, C., and Kim, H. 1998. Identification of the imperfect stage of Mycosphaerella nawae causing circular leaf spot of persimmon in Korea. Korean J. Plant Pathol. 14:397-401.

19. Kwon, J. H., and Park, C. S. 2004. Ecology of disease outbreak of circular leaf spot of persimmon and inoculum dynamics of Mycosphaerella nawae. Res. Plant Dis. 10:209-216. (In Korean, abstract in English).

20. Madden, L. V., and Ellis, M. A. 1988. How to develop plant disease forecasters. Pages 190-208 in: Experimental Techniques in Plant Disease Epidemiology. J. Kranz and J. Rotem, eds. Springer-Verlag, Berlin.
21. Madden, L. V., and Wheelis, M. 2003. The threat of plant pathogens as weapons against US crops. Annu. Rev. Phytopathol. 41:155-176.

22. Magarey, R. D., Fowler, G. A., Borchert, D. M., Sutton, T. B., and Colunga-Garcia, M. 2007. NAPPFAST: An internet system for the weather-based mapping of plant pathogens. Plant Dis. 91:336-345.

23. Magarey, R. D., Sutton, T. B., and Thayer, C. L. 2005. A simple generic infection model for foliar fungal plant pathogens. Phytopathology 95:92100.

24. Makowski, D., Denis, J.-B., Ruck, L., and Penaud, A. 2008. A Bayesian approach to assess the accuracy of a diagnostic test based on plant disease measurement. Crop Prot. 27:1187-1193.

25. Marjoram, P., Molitor, J., Plagnol, V., and Tavare, S. 2003. Markov chain Monte Carlo without likelihoods. Proc. Natl. Acad. Sci. USA 100:1532415328 .

26. Mila, A. L., and Carriquiry, A. L. 2004. Bayesian analysis in plant pathology. Phytopathology 94:1027-1030.

27. Mila, A. L., and Michailides, T. J. 2006. Use of Bayesian methods to improve prediction of panicle and shoot blight severity of pistachio in California. Phytopathology 96:1142-1147.

28. Pinkard, E. A., Kriticos, D. J., Wardlaw, T. J., Carnegie, A. J., and Leriche, A. 2010. Estimating the spatio-temporal risk of disease epidemics using a bioclimatic niche model. Ecol. Model. 221:2828-2838.

29. Pivonia, S., and Yang, X. B. 2004. Assessment of the potential year-round establishment of soybean rust throughout the world. Plant Dis. 88:523529.

30. Rotem, J. 1978. Climatic and weather influences on epidemics. Pages 317-337 in: Plant Disease. An Advanced Treatise vol. II. How Disease Develops in Populations. J. G. Horsfall and E. B. Cowling, eds. Academic Press, Inc., New York.

31. Scherm, H., and Yang, X. B. 1999. Risk assessment for sudden death syndrome of soybean in the north-central United States. Agric. Syst. 59:301-310.

32. Venette, R. C., and Cohen, S. D. 2006. Potential climatic suitability for establishment of Phytophthora ramorum within the contiguous United States. Forest Ecol. Manag. 231:18-26.

33. Vicent, A., and Makowski, D. 2010. Adaptabilidad climática y análisis de riesgos de nuevas enfermedades. Estudio particular de la mancha foliar del kaki causada por Mycosphaerella nawae. Page 111 in: XV Congreso de la Sociedad Española de Fitopatología Vitoria-Gasteiz, Spain.

34. Watt, M. S., Kriticos, D. J., Alcaraz, S., Brown, A. V., and Leriche, A. 2009. The hosts and potential geographic range of Dothistroma needle blight. Forest Ecol. Manag. 257:1505-1519.

35. Yang, X. B., Dowler, W. M., and Royer, M. H. 1991. Assessing the risk and potential impact of an exotic plant disease. Plant Dis. 75:976-982.

36. Yonow, T., Kriticos, D. J., and Medd, R. W. 2004. The potential geographic range of Pyrenophora semeniperda. Phytopathology 94:805-812. 